\section{SP3-38 IMPROVED PREGNANCY DANGER SIGN KNOWLEDGE ENHANCES FACILITY DELIVERY IN RURAL BANGLADESH}

doi:10.1136/jech.2011.142976o.38

A Rahman.* International center for Diarrhoeal Disease Research Bangladesh, Dhaka, Bangladesh

Introduction Achieving Millennium Development Goal 5 is crucial for Bangladesh. Knowledge about pregnancy danger signs is essential in avoiding maternal death. Currently Bangladesh is addressing selected pregnancy danger signs across the nation. The objective of this study was to determine the effect of improved pregnancy danger sign knowledge on institutional delivery.

Methods The International Center for Diarrhoeal Disease Research Bangladesh has been maintaining a Health and Demographic Surveillance System (HDSS) since 1966. A maternal, child health and family planning programme was introduced in 1977 in half of the HDSS area. A pictorial pregnancy follow-up card was introduced in 1987 and five selected pregnancy danger signs (bleeding, headache, oedema, mal-presentation, prolonged labour) pictures were included in 2000. The service providers asked each woman about each picture during her 1 st \& succeeding antenatal care visit.

Results 5538 women who gave birth during 2003 and 2004 were included in the analysis. Knowledge of at least one pregnancy danger sign was increased from $6.7 \%(192 / 2841)$ to $38.5 \%(1103 / 2865)$ in 2003 and $7.5 \%(196 / 2610)$ to $45.3 \%(1212 / 2673)$ in 2004 at first and succeeding visits respectively. Those women who knew at least one pregnancy danger sign were 1.34 (OR $1.34,95 \%$ CI 1.05 to 1.71 ) and 1.21 (OR $1.21,95 \%$ CI 1.07 to 1.36 ) times more likely to have a facility delivery than who didn't (adjusted).

Conclusion Bangladesh should aim to make the pictorial tool available in rural area and ensure to ensure that women understand the danger messages.

\section{SP3-39 VARIATIONS OF AVOIDABLE MORTALITY IN RUSSIA}

doi:10.1136/jech.2011.1429760.39

T Sabgayda, ${ }^{*}$ V Semyonova. Federal State Statistics Service, Moscow, Russia

Variation of avoidable mortality in Russia and its relation to socioeconomic conditions was analysed using official mortality data. Avoidable mortality in 2009 was 538.6 on 100000 population for men and 177.4 for women, it is much more that in Europe. In age group 5-64 years avoidable deaths comprise $56.4 \%$ of all deaths (PP rate) for men and $53.3 \%$ of all deaths for women, varying among Russian regions from $45.4 \%$ to $69.3 \%$ and from $40.0 \%$ to $68.8 \%$ for men and women. $79.3 \%$ of avoidable deaths among Russian men is determined by the first group of causes of death related to primary prevention (M1); $0.4 \%$ is determined by the group of causes related to early diagnosis (M2); $20.3 \%$ is determined by the group of causes related to the quality of healthcare (M3). For women, these percentages are $67.6,14.9$ and 17.6 respectively. The highest and the lowest M1 are $34.7 \%$ and $59.8 \%$ for men, $19.5 \%$ and $56.7 \%$ for women. The lowest $\mathrm{M} 2$ are $0.001 \%$ for men $2.4 \%$ and for women, the highest $\mathrm{M} 2$ are $0.6 \%$ for men and $14.9 \%$ for women. The lowest M3 are 7.0\% for men and $5.8 \%$ for women, the highest $\mathrm{M} 3$ are $15.9 \%$ for men and $16.3 \%$ for women. This data show that only the M1 is substantially higher in regions with low socio-economic level compared to wealthier regions. Mortality in disadvantaged regions from the first group of avoidable causes exceeds that in wealthy regions by $203.0 \%$ for men and by $238.3 \%$ for women.

\section{SP3-40 DISABILITY-FREE LIFE EXPECTANCY AND RELATED FACTORS IN JAPAN}

doi:10.1136/jech.2011.1429760.40

${ }^{1} \mathrm{~T}$ Noda, ${ }^{1} \mathrm{~T}$ Ojima, ${ }^{2} \mathrm{~S}$ Hashimoto, ${ }^{2} \mathrm{M}$ Kawado, ${ }^{3} \mathrm{R}$ Seko, ${ }^{4} \mathrm{M}$ Kato, ${ }^{1} \mathrm{C}$ Murata ${ }^{1} \mathrm{~S}$ Hayasaka, ${ }^{5} \mathrm{M}$ Hayashi, ${ }^{6} \mathrm{Y}$ Murakami, ${ }^{7} \mathrm{M}$ Nagai, ${ }^{7}$ I Tsuji. ${ }^{1}$ Hamamatsu University School of Medicine, Hamamatsu, Japan; ${ }^{2}$ Fujita Health University School of Medicine, Toyoake, Japan; ${ }^{3}$ Fujita Health University School of Health Sciences, Toyoake, Japan; ${ }^{4}$ Tsushima Public Health Center, Tsushima, Japan; ${ }^{5}$ Fukushima Medical University School of Nursing, Fukushima, Japan; ${ }^{6}$ Shiga University of Medical Science, Otsu, Japan; ${ }^{7}$ Tohoku University Graduate School of Medicine, Sendai, Japan

Introduction Disability-free life expectancy (DFLE) is an average number of years that a person can expect to live in "full health." The Japanese government asked all 47 prefectures to reflect DFLE in their health policies. To meet this political demand, we estimated DFLE of all the prefectures in Japan by the data of the Long-Term Care Insurance System implemented in 2000 and examined socio-demographic and health factors which might influence DFLE.

Methods We assumed those who were under the conditions of Need for Long-Term Care (category 2 or more) as "disabled." DFLE at age 65 (DFLE-65) was estimated by Sullivan's method which used the proportion of the stationary population of the non-disabled to the number of survivals from life table by age and sex. For evaluating factors potentially influencing DFLE-65, we conducted an ecological study of all 47 prefectures in Japan with several national statistics. Results DFLE-65 in Japan in 2005 were 16.6, 20.2, and 18.4 years for male, female, and overall, respectively. In 2009, such figures were 17.1, 20.5, and 18.8 years, respectively. DFLE-65 in 2009 was strongly correlated with several causes of death, number of snowy days, and several healthy habits. The difference of DFLE-65 from 2005 to 2009 was strongly correlated with healthy dietary habits, exercise, income per capita, and snowy or rainy days.

Conclusion In Japan, DFLE-65 is still in an upward phase and implementation of healthy dietary habits and exercise might prolong the DFLE.

\section{SP3-41 AUTONOMY AS A PREDICTIVE FACTOR FOR OLDER PERSONS' SURVIVAL}

doi:10.1136/jech.2011.1429760.41

${ }^{1} \mathrm{~T}$ Ruiz, ${ }^{2} \mathrm{~J}$ E Corrente. 'Department of Public Health, Botucatu School of Medicine, UNESP, Botucatu, Sao Paulo, Brazil; ${ }^{2}$ Department of Biostatistics, Botucatu Biosciences Institute, UNESP, Botucatu, Sao Paulo, Brazil

Introduction As reported by the literature, chronic diseases are related to the survival time of older populations.

Objective To study the association of autonomy, depression cognition loss and alcoholism with older persons' survival in a mediumsized city in São Paulo state (BRAZIL)

Methodology Systematic population sampling for unknown prevalence was performed. Three hundred and sixty-five people aged 60 years and older were interviewed by means of home enquiries in 2006-2007. The Activities of Daily Living (ADL) Scale (Katz Downs et al, 1970), Instrumental Activities of Daily Living (IADL) Scale (Lawton and Brody, 1969), Abridged Geriatric Depression Scale (Yesavage JA, Brink TL et al, 1982), Mini-Mental Status Examination (MMSE) (Folstein, Folstein et al, 1975; Bertolucci, Brucki et al, 1994) and the CAGE Alcohol Use Assessment (Ewing, 1984) were applied. As to survival, the log-rank test was performed, and the proportionality of the curves for each one of the evaluations was observed. Next, they were conjointly studied by the Cox model and adjusted by gender and age.

Results 3 years after the enquiry, the $\mathrm{ADL}$ and $\mathrm{IADL}$ evaluations generated proportional survival curves. Only ADLs showed to be a 